Synthesis of Natural

Products and

Potential Drugs

\title{
Synthesis of Gymnocin-A
}
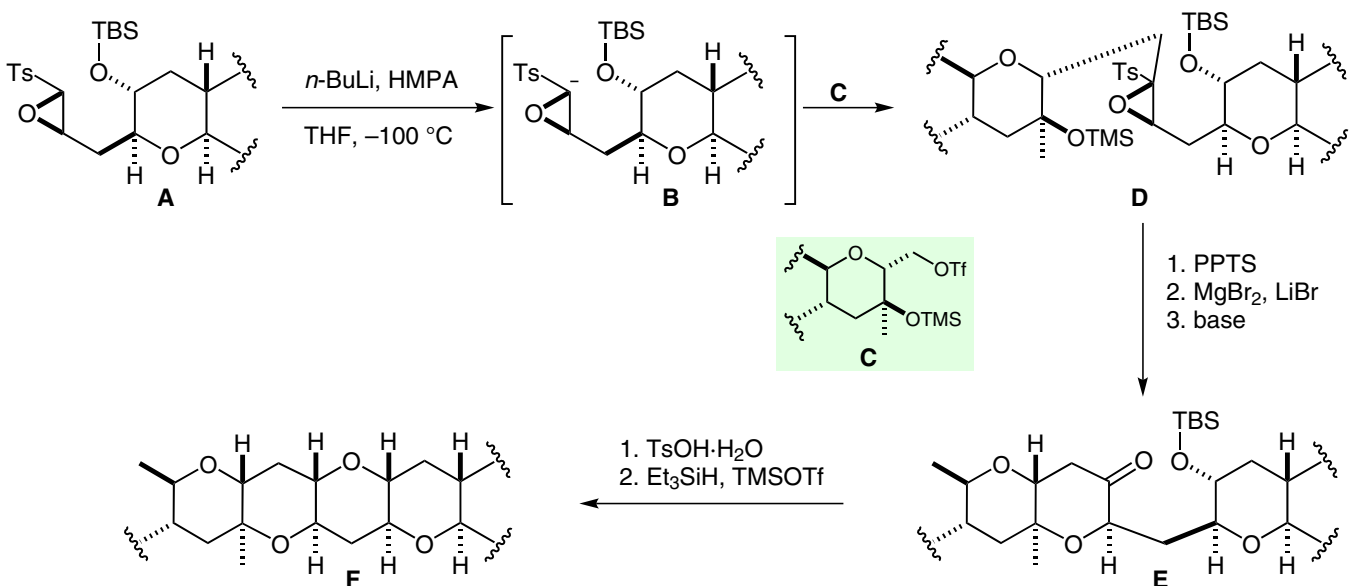

1. $\mathrm{TsOH} \cdot \mathrm{H}_{2} \mathrm{O}$ 2. $\mathrm{Et}_{3} \mathrm{SiH}, \mathrm{TMSOTf}$
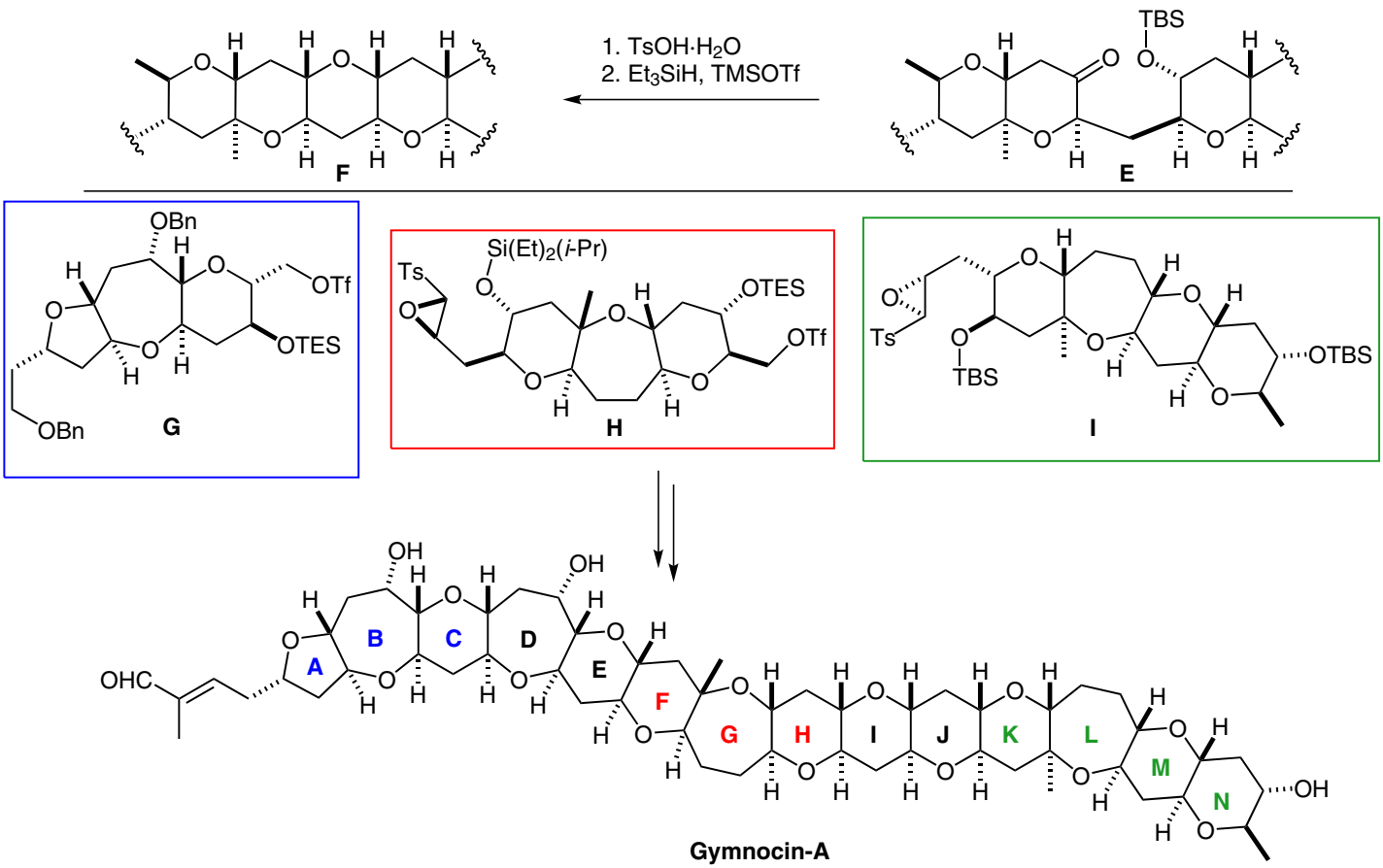

Significance: Gymnocin-A, a polycyclic ether isolated from Karenia mikimotoi in 2002, exhibits strong cytoxicity $\left(\mathrm{IC}_{50}=1.3 \mu \mathrm{g} / \mathrm{mL}\right)$ against mouse leukemia cells. Structurally, this natural product is characterized by 14 consecutive ether rings. Thus far, only one total synthesis has been reported (C. Tsukano, M. Sasaki J. Am. Chem. Soc. 2003, 125, 14294). Herein, Mori and coworkers present a strategically different approach, relying on the union of the three fragments $\mathbf{G}, \mathbf{H}$, and I by an oxiranyl anion coupling.

\section{Key words}

gymnocin-A

polycyclic ether

oxiranyl anions

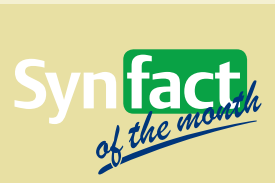

Comment: The presented synthesis is centered around a multi-step coupling protocol uniting two fragments and concomitantly forming two new cyclic ethers in between. Thereby, a tosyl epoxide of type $\mathbf{A}$ was deprotonated and reacted with triflate C, generating D. Acid-mediated TMS deprotection, epoxide opening, and ether formation then yielded ketone $\mathbf{E}$. The second ether ring was ultimately formed by acid-mediated hemiacetalization and reduction with $\mathrm{Et}_{3} \mathrm{SiH}$. 